Original article

\title{
Chitosan-pectin polyelectrolyte complex as a carrier for colon targeted drug delivery
}

\author{
Sonia Pandey*, Ashish Mishra, Pooja Raval, Hetal Patel, Arti Gupta, Dinesh Shah \\ Maliba Pharmacy College, Surat, Gujarat 394350, India
}

\section{A R T I C L E I N F O}

\section{Article history:}

Received 29 August 2013

Accepted 16 November 2013

Available online 28 December 2013

\section{Keywords:}

Polyelectrolyte complex (PEC)

Chitosan

Pectin

Colon targeted drug delivery

\begin{abstract}
A B S T R A C T
Objective: The objective of present work was to prepare a polyelectrolyte complex (PEC) between chitosan (polycation) \& pectin (polyanion) and to develop enteric coated tablets for colon delivery using the PEC.

Methodology: The PECs were prepared using different concentrations of chitosan and pectin. Drug loaded enteric coated tablets were prepared by wet granulation method using PEC to sustain the release at colon and coating was done with Eudragit S 100 to prevent the early release of the drug in stomach and intestine. Two independent variable, \% PEC (chitosan/pectin) and \% coating were optimized by $3^{2}$ full factorial design. Statistical model were also used to supplement the optimization. DSC was performed to confirm the interaction between the polyions. Developed formulations were evaluated for physical appearance, weight variation, thickness, hardness, friability, \% swelling, assay, in-vitro and ex-vivo drug release studies to investigate the PEC's ability to deliver the drug to colon. Ex-vivo release study using rat caecal content was also carried out on optimized formulation.

Results and discussion: DSC results confirmed chitosan/pectin interaction and subsequent formation of PEC. The optimized formulation containing $1.1 \%$ of PEC and 3\% of coating showed highest swelling and release in alkaline $\mathrm{pH}$ mechanism of which was found to be microbial enzyme dependent degradation established by ex-vivo study using rat caecal content.
\end{abstract}

Copyright @ 2013, InPharm Association, Published by Reed Elsevier India Pvt. Ltd. All rights reserved.

\section{Introduction}

In the development of colon targeted delivery interpolymer complex (IPC) hydrogels have generated considerable interest as vehicle for drug delivery. IPC provides free volume space for the easy encapsulation of drugs in its three-dimensional network structure commonly known as polyelectrolyte complex (PEC) obtained by cross-linking of two or more polymers. ${ }^{1}$ The colon provides a site for drug delivery, with distinct advantages of a near neutral $\mathrm{pH}$, a much longer transit time, relatively low photolytic enzyme activity, and greater responsiveness to absorption enhancers. Colon-specific delivery systems would prevent release of the drug in the upper-part of GIT but would require a triggering mechanism to affect an abrupt release on reaching the colon. ${ }^{2,3}$ The successful targeted delivery of drugs to the colon via the gastrointestinal tract (GIT) requires the protection of a drug from degradation and release in the stomach and small intestine and then

\footnotetext{
* Corresponding author. Tel.: +91 9725128861 (mobile); fax: +91 (0) 2625 255882.

E-mail address: sonia.pandey@utu.ac.in (S. Pandey).
}

ensures abrupt or controlled release in the proximal colon. ${ }^{4}$ Various properties of IPCs such as porosity, bio-adhesiveness, elasticity, swelling and stimuli-responsive behavior can be controlled by the appropriate choice of the network-forming polymers. ${ }^{5} \mathrm{~F}$. Bigucci et al (2008) have also earlier prepared chitosan/pectin polyelectrolyte complexes for colon-specific delivery of vancomycin but the present work focuses on economizing the development of drug loaded enteric coated tablets of PEC.

Several natural polysaccharides are extensively used to prepare the PEC. Chitosan is soluble at low pH of stomach hence there is a need to make enteric coated formulation that would protect it from stomach's environment. A coating with $\mathrm{pH}$ dependent polymer Eudragit S100 was done to prevent the early release of drug in stomach and intestine. As chitosan alone cannot provide sustained release at the site, pectin was used for cross-linking to formulate PEC. Pectin is highly water soluble, absorbed in the upper GIT, and completely degraded by the colonic bacterial enzymes. Accounting for all properties of PEC and coating polymer, tablets were prepared using various concentrations of PEC. The developed formulation showed $\mathrm{pH}$ dependent swelling and release in alkaline $\mathrm{pH}$. Ex-vivo confirmed that polysaccharide degradation by colonic microbial enzyme was the prime source of drug release in colon. ${ }^{6}$ 


\section{Materials and methods}

\subsection{Materials}

Theophylline was a gift from Sidmak Pharma, Vapi, India. Low molecular weight (LMW) chitosan (molecular weight $=50-190 \mathrm{kDa}$ ) was obtained from Balaji Drugs Ltd., Mumbai, India. Pectin, sodium hydroxide, glacial acetic acid, sodium acetate, sodium starch glycolate (SSG), potassium dihydrogen phosphate, magnesium stearate were obtained from S.D Fine Chemicals Ltd. Erythrosine was bought from Yarrow Chemicals Ltd, India. Talc was obtained from Chem Port Pte. Ltd., India. All other chemicals used were of analytical grade.

\subsection{Drug - excipients compatibility study}

\subsubsection{Fourier transform infrared spectroscopy (FT-IR)}

Compatibility of theophylline with the individual excipients was established by FT-IR. Any change in the chemical composition after combining with excipients was investigated with IR spectral analysis. The IR spectra of drug and drug + excipients were recorded in FT-IR (Bruker Optics Alpha) in the range of $4000-500 \mathrm{~cm}^{-1}$.

\subsection{Preparation of chitosan/pectin IPC}

Chitosan solution $(1 \% \mathrm{w} / \mathrm{v})$ was prepared in acetic acid. Pectin solution $(5 \% \mathrm{w} / \mathrm{v})$ was prepared in distilled water. Both the solutions were sonicated separately till their clear solutions were obtained. After that both solutions were mixed, agitated for $30 \mathrm{~min}$ and then kept for drying for $5 \mathrm{~h}$ to yield a dry powder.

\subsection{Characterization of IPC}

\subsubsection{By DSC}

Chitosan, pectin and PEC were subjected to DSC study using Shimadzu DSC 60 (Kyoto, Japan). $10 \mathrm{mg}$ sample was heated in aluminum pan at a rate of $20^{\circ} \mathrm{C} / \mathrm{min}$ in the temperature range of $50-300{ }^{\circ} \mathrm{C}$ under the nitrogen flow of $40 \mathrm{ml} / \mathrm{min}$.

\subsection{Tablet preparation}

Drug and all excipients except PEC were passed through the 60 \# sieve, and then PEC was mixed. Dry mass was granulated using isopropyl alcohol. The granules so obtained were dried at $50{ }^{\circ} \mathrm{C}$ for $1 \mathrm{~h}$ in the oven. Dried granules were passed through 22 \# sieve and fines were separated using 44 \# sieve. SSG was passed through 60 \# sieve and mixed with dried granules. These granules were lubricated with magnesium stearate and talc. The lubricated granules were compressed into tablets using tablet compression machine (Rimek Mini Press-I, India). Weight variation, hardness, friability and disintegration test were performed for the core tablets. Formulation composition of the tablet is given in Table 1 .

\subsection{Preparation of coating solution}

Coating solution was made by dissolving Eudragit S100 in isopropyl alcohol. A bath sonicator was used to homogenize the coating solution. After sonication PEG $400(1.25 \% \mathrm{v} / \mathrm{v})$ as plasticizer,
Table 1

Tablet composition.

\begin{tabular}{ll}
\hline Ingredient & Quantity \\
\hline Theophylline & $100 \mathrm{mg}$ \\
Sodium starch glycolate & $4 \% \mathrm{w} / \mathrm{w}$ \\
Chitosan:pectin IPC $(1: 5)(\% \mathrm{w} / \mathrm{w})$ & $1 \%, 2 \%, 3 \%$ \\
Magnesium stearate & $0.02 \mathrm{~g}$ \\
Talc & $0.01 \mathrm{~g}$ \\
Lactose monohydrate q.s & $400 \mathrm{mg}$ \\
\hline
\end{tabular}

Manufacturers, India). The spray dispersion was maintained at a rate of $4-8 \mathrm{ml} / \mathrm{min}$ and bed temperature of $35-40{ }^{\circ} \mathrm{C}$ at $35 \mathrm{rpm}$. The $3^{2}$ full factorial design was employed in which two factors were evaluated, each at 3 levels and experimental trials were performed at all 9 possible combinations. The amount of PEC and \% coating were selected as independent variables while drug release at $4 \mathrm{~h}$ $\left(Q_{4}\right)$ and at $12 \mathrm{~h}\left(Q_{12}\right)$ were selected as dependent variables (Table $2 \mathrm{a}$ and $\mathrm{b})$.

As shown in Eq. (1), a statistical model incorporating interactive and polynomial terms was used to evaluate the responses.

$Y=\beta_{0}+\beta_{1} X_{1}+\beta_{2} X_{2}+\beta_{3} X_{1} X_{2}+\beta_{4} X_{1}^{2}+\beta_{5} X_{2}^{2}+\beta_{6}$

$X_{1}^{2} X_{2}+\beta_{7} X_{1} X_{2}^{2}+\beta_{8} X_{1}^{2} X_{2}^{2}$

where, $Y$ is dependent variable, $b_{0}$ is arithmetic mean response, $\beta_{1}$ is coefficient of factor $X_{1}$, The main effects $X_{1}$ and $X_{2}$ represent the average result of changing one factor at a time from its low to high value. The interaction terms, $X_{1} X_{2}, X_{1}^{2} X_{2}, X_{1} X_{2}^{2}$ and $X_{1}^{2} X_{2}^{2}$, show how the dependent variable changes when two or more factors are simultaneously changed. Statistical analysis was done using Microsoft Excel 2007. Contour plots and response surface plots were drawn using Design Expert software. ${ }^{7-9}$

\subsection{Evaluation of core tablets}

Core tablets were evaluated for appearance, diameter, thickness, weight variation, hardness, friability, hardness, disintegration, drug content and content uniformity test. Weight variation test and disintegration test were performed as per USP. ${ }^{10,11}$ Hardness, thickness and friability were determined by Monsanto Hardness Tester, Digital Vernier Calipers and Roche Friabilator, respectively.

\subsubsection{Swelling study}

Three tablets from each batch were weighted accurately and immersed in dissolution medium $(100 \mathrm{ml}$ of $0.1 \mathrm{~N} \mathrm{HCl})$ for $2 \mathrm{~h}$. For next $1 \mathrm{~h}$ tablets were kept in acetate buffer ( $\mathrm{pH} 4.6$ ), after that for next $4 \mathrm{~h}$ tablets were placed in phosphate buffer $(\mathrm{pH} \mathrm{6.8)}$ ) and then onwards tablets were placed in phosphate buffer $(\mathrm{pH} 7.4)$ for next $5 \mathrm{~h}$. Tablets were taken out carefully after each time interval up to $12 \mathrm{~h}$, blotted with filter paper to remove the fluid present on the surface and weighed accurately. Percentage swelling (swelling index) was calculated using the following formula. ${ }^{12}$

$\%$ Swelling index $=\frac{\text { Wet weight of tablet }- \text { Dry weight of tablet }}{\text { Dry weight of tablet }} \times 100$

was added to the solution. The coating solution so prepared was applied on tablets by intermittently spraying it through a pilot type spray gun fitted with $1 \mathrm{~mm}$ spray nozzle in pan coater (Hardik
2.7.2. Drug release study

2.7.2.1. In-vitro drug release study of Eudragit S 100 coated tablets. In-vitro dissolution studies of coated tablets were carried out using 
Table 2a

Layout of factorial design.

\begin{tabular}{llll}
\hline \multicolumn{3}{l}{ Translation of coded values in actual units } & \\
\hline Independent variables & \multicolumn{2}{l}{ Levels used, actual (coded) } \\
\cline { 2 - 4 } & Low $(-1)$ & Medium $(0)$ & High $(+1)$ \\
\hline $\mathrm{X}_{1}=$ amount of PEC & 1 & 2 & 3 \\
$\mathrm{X}_{2}=\%$ of coating & $3 \%$ & $5 \%$ & $7 \%$ \\
Dependent variables & & & \\
1. Percentage cumulative release at $4 \mathrm{~h}\left(Q_{4}\right)$ & & \\
2. Percentage cumulative release at $12 \mathrm{~h}\left(Q_{12}\right)$ & \\
\hline
\end{tabular}

Table 2b

$3^{2}$ Full factorial design matrix with interaction terms.

\begin{tabular}{llllll}
\hline Batch & $X_{1}$ & $X_{2}$ & $X_{12}$ & $X_{11}$ & $X_{22}$ \\
\hline F1 & -1 & -1 & +1 & +1 & +1 \\
F2 & 0 & -1 & 0 & 0 & +1 \\
F3 & +1 & -1 & -1 & +1 & +1 \\
F4 & -1 & 0 & 0 & +1 & 0 \\
F5 & 0 & 0 & 0 & 0 & 0 \\
F6 & +1 & 0 & 0 & +1 & 0 \\
F7 & -1 & +1 & -1 & +1 & +1 \\
F8 & 0 & +1 & 0 & 0 & +1 \\
F9 & +1 & +1 & +1 & +1 & +1 \\
\hline
\end{tabular}

dissolution test apparatus USP I paddle type. The dissolution medium consisted of $900 \mathrm{ml}$ of $\mathrm{pH} 1.2$ for first $2 \mathrm{~h}$ followed by $\mathrm{pH} 4.6$ and 6.8 phosphate buffers for 1 and $3 \mathrm{~h}$ respectively and finally $\mathrm{pH} 7.4$ phosphate buffer for the remaining time period up to $12 \mathrm{~h}$. The temperature of the medium was maintained at $37 \pm 0.5^{\circ} \mathrm{C}$ and the speed of rotation of the basket was $50 \mathrm{rpm}$. Aliquots of $10 \mathrm{ml}$ were withdrawn after every hour and replaced with the fresh dissolution medium equilibrated at the same temperature. The absorbance of the samples was determined at wavelength according to the dissolution medium $\mathrm{pH} 1.2\left(\lambda_{\max }=263 \mathrm{~nm}\right), 4.6\left(\lambda_{\max }=271 \mathrm{~nm}\right), 6.8\left(\lambda_{\max }=272 \mathrm{~nm}\right)$ and $7.4\left(\lambda_{\max }=267 \mathrm{~nm}\right)$ using UV-Visible spectrophotometer (UV-1800, Shimadzu) against respective buffer solutions as a blank.

\subsection{Release drug data modeling}

\subsubsection{Korsmeyer-Peppas model ${ }^{13}$}

$\frac{M t}{M \infty}=k t^{n}$ where, $k$ is the rate constant and $n$ is release exponent that characterizes the mechanism of drug release. For cylindrical matrix tablets, if $n=0.45$ it indicates drug release mechanism by Fickian diffusion, and if $0.45<n<0.89$, it is non-Fickian or anomalous diffusion.

\subsection{Ex-vivo release study}

The drug release studies were carried out using USP dissolution rate test apparatus (apparatus 1, $100 \mathrm{rpm}, 37 \pm 0.5{ }^{\circ} \mathrm{C}$ ). Each formulations after completing the dissolution study in $0.1 \mathrm{~N} \mathrm{HCl}(2 \mathrm{~h})$, acetate buffer $\mathrm{pH} 4.6(1 \mathrm{~h})$ and phosphate buffer $\mathrm{pH} 6.8(3 \mathrm{~h})$ was placed in the basket of the apparatus and immersed in $4 \%$ rat cecal content medium (phosphate buffer $\mathrm{pH}$ 7.4). At fixed time intervals, $10 \mathrm{ml}$ of sample was withdrawn, replaced with $10 \mathrm{ml}$ of fresh phosphate buffer $\mathrm{pH} 7.4$ and the experiment was continued for another $6 \mathrm{~h}$. Sample was filtered and analyzed for theophylline by UV Spectrophotometer at $263 \mathrm{~nm}, 271 \mathrm{~nm}, 272 \mathrm{~nm}, 267 \mathrm{~nm}$ for $0.1 \mathrm{~N} \mathrm{HCl}$, acetate buffer $\mathrm{pH} 4.6$, phosphate buffer $\mathrm{pH} 6.8$ and phosphate buffer $\mathrm{pH} 7.4$ respectively. ${ }^{14}$

\section{Results and discussion}

\subsection{By FT-IR}

The FT-IR spectra of theophylline, excipient mixture and theophylline and excipient mixture have been shown in Fig. 1. The spectra exhibited no change in the absorption peaks of theophylline vis-à-vis the theophylline + excipient mix so it can be concluded that there is no interaction between the components.

\subsection{Characterization of prepared IPC}

\subsubsection{By DSC}

The chitosan showed the first melting point peak at $56.7^{\circ} \mathrm{C}$ and second at $312{ }^{\circ} \mathrm{C}$. Pectin showed broad peak at $238^{\circ} \mathrm{C}$. DSC curve of PEC mixture (IPC) of chitosan and pectin showed peak at $215^{\circ} \mathrm{C}$. The results of DSC are in compliance with observations of Ghaffari et $\mathrm{al}^{15}$ who had reported interaction (chitosan and pectin) temperature in the range of $210-220^{\circ} \mathrm{C}$. The shift to lower temperature in melting point peak of the complex indicates that the probable formation of ionic bonds between chitosan and pectin is correlated to the loss of organization (Fig. 2). ${ }^{16}$

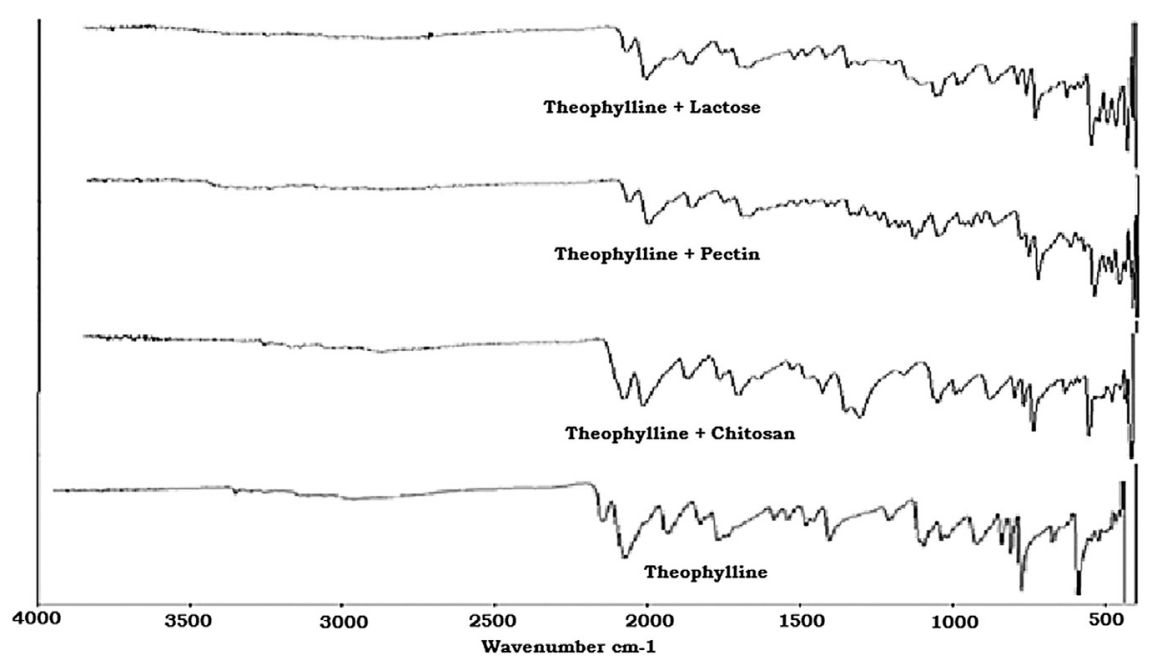

Fig. 1. FT-IR spectra of theophylline and excipient mixture. 


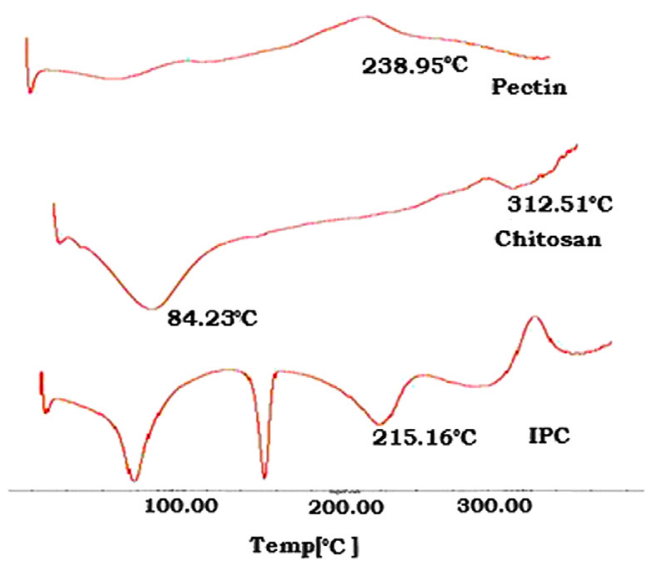

Fig. 2. DSC graph of pectin, chitosan, IPC.

\subsubsection{Evaluation of physical properties of tablets}

Table 3 lists the physical properties (thickness, diameter, weight, hardness, friability) and \% assay of tablet. They produced with small weight variations (less than 6\%); uniform thickness and hardness; acceptable friability (less than 1\%) and \% drug content. The average weight of tablet formulation was within the range of $387.6 \pm 0.028$ to $410.7 \pm 0.091 \mathrm{mg}$. The hardness of the tablets ranged between $6.9 \pm 0.14$ to $7.4 \pm 0.14 \mathrm{~kg} / \mathrm{cm}^{2}$. In case of content uniformity test, drug content was found to be within $95.5 \pm 0.03 \%$ to $98.23 \pm 0.023 \%$ of labeled amount.

\subsubsection{Swelling studies}

The enteric coated tablets showed $\mathrm{pH}$ sensitive swelling behavior. The degree of swelling is mainly affected by $\mathrm{pH}$ of the medium, type of anionic polymer and amount of IPC (chitosan and pectin). As pH of the swelling medium changes (1.2, 4.6, 6.8 and 7.4) the degree of interaction between chitosan and pectin is modified and swelling occurs because of the dissociation of the complex. In acidic medium, pectin is neutralized and free positive charge $\left(\mathrm{NH}^{+}\right)$appears inside the gel; while in basic medium, chitosan is neutralized and free negative charge $\left(\mathrm{COO}^{-}\right)$appears inside the gel. The mutual repulsion between positive or negative charges and the entry of water together with counterions to neutralize these charges cause swelling. All the tablets showed low swelling in $\mathrm{pH}$ $1.2(0.1 \mathrm{~N} \mathrm{HCl}), \mathrm{pH} 4.6$ (acetate buffer) and pH 6.8 (phosphate buffer). In pH 7.4 (phosphate buffer), the degree of swelling was increased due to deprotonation of chitosan. It was observed that as the concentration of IPC increased the swelling index decreased. Batch F4 (2\% IPC, 5\% coating) showed maximum swelling index of $79.51 \pm 1.61 \%$. Thus IPC tablet is hydrophilic and swells considerably in phosphate buffer solutions. This process shows a pH-dependent pattern. There also exists the possibility of intramolecular hydrogen bonding between the $\mathrm{OH}$ or $\mathrm{COOCH}_{3}$ groups within the network of
Table 4

Evaluation of enteric coated tablets.

\begin{tabular}{|c|c|c|c|}
\hline Batch code & $\begin{array}{l}\text { Weight of tablet }{ }^{\mathrm{a}} \\
(\mathrm{mg})(n=20)\end{array}$ & $\%$ Coating & $\begin{array}{l}\text { Disintegration time in } \\
\text { pH } 7.4 \text { phosphate buffer }\end{array}$ \\
\hline $\mathrm{F} 1$ & $412.25 \pm 1.62$ & 3 & $25 \min 58 \mathrm{~s}$ \\
\hline F2 & $420.32 \pm 1.25$ & 5 & $32 \min 42 \mathrm{~s}$ \\
\hline F3 & $428.86 \pm 1.54$ & 7 & $38 \mathrm{~min} 21 \mathrm{~s}$ \\
\hline $\mathrm{F} 4$ & $412.14 \pm 0.24$ & 3 & $28 \mathrm{~min} 34 \mathrm{~s}$ \\
\hline F5 & $420.28 \pm 0.53$ & 5 & $35 \mathrm{~min} 28 \mathrm{~s}$ \\
\hline F6 & $428.58 \pm 0.18$ & 7 & $40 \min 14 \mathrm{~s}$ \\
\hline F7 & $412.21 \pm 0.23$ & 3 & $30 \min 84 \mathrm{~s}$ \\
\hline F8 & $420.38 \pm 0.75$ & 5 & $38 \min 54 \mathrm{~s}$ \\
\hline F9 & $428.67 \pm 0.90$ & 7 & $44 \mathrm{~min} 25 \mathrm{~s}$ \\
\hline
\end{tabular}

a Value expressed as mean \pm SD.

the IPC. However, at $\mathrm{pH} 7.4$, the $-\mathrm{NH}_{2}$ group of chitosan will be partially unionized. Therefore, at this $\mathrm{pH}$, the IPC network will be loose as a result of suboptimal $\mathrm{NH}_{3}^{+}--\mathrm{OOC}$ ionic interaction. In other words, stronger ionic interaction may result in a tightening of the IPC network leading to a reduced swelling capacity at $\mathrm{pH} 6.8$ as compared with $\mathrm{pH}$ 7.4.

\subsubsection{Evaluation of enteric coated tablets}

Tablets weight, \% coating and disintegration time of coated second pulse tablets are reported in Table 4. Weight variation of enteric coated tablets for all batches (F1 to F9) was below 3\%. The weight gain calculated from the average tablet weight for \% Coating was found to be in the range of $3-7 \%$. In the disintegration test, all the tablets remained intact in $0.1 \mathrm{~N} \mathrm{HCl}$ for a $1 \mathrm{~h}$ and showed no cracks or fracture. Same tablets disintegrated within $45 \mathrm{~min}$ in $\mathrm{pH} 7.4$ indicating that the disintegration time in $\mathrm{pH} 7.4$ increased with increase in \% weight. Eudragit S 100 was used in the preparation to target the colon. Isopropyl alcohol was used as a solvent for the coating dispersion due to its high flash point $\left(15^{\circ}\right)$, low boiling point $\left(82.3^{\circ}\right)$, and low heat of evaporation $(667 \mathrm{~J} / \mathrm{g}$ ). Eudragit is a brittle polymer hence it was needed to lower the glass transition temperature of polymer and promote formation of a good elastic film. Polymer softening tendencies stimulate sticking at higher temperature, so the bed temperature was maintained at $35-40{ }^{\circ} \mathrm{C}$ using an infrared lamp. To get fine spray droplets the spray nozzle of $1 \mathrm{~mm}$ was used at an atomization air pressure of $4 \mathrm{~kg} / \mathrm{cm}^{2}$. By controlling the rotating pan at speed of $20 \mathrm{rpm}$ and the rate of spray dispersion application the sticking tendency of the tablets was overcome.

\subsubsection{Drug release study}

3.2.5.1. In-vitro drug release of factorial batches. All the formulations were evaluated for in-vitro drug release. The cumulative \% theophylline release, from all 9 formulations as the function of the time is shown in Fig. 3.

Cumulative drug release profile of factorial batches (F1 to F9) showed sigmoidal drug release pattern (Fig. 3). The in-vitro release of drug from formulations was mainly affected by concentration of

Table 3

Evaluation parameters of tablet.

\begin{tabular}{|c|c|c|c|c|c|c|c|}
\hline Batch & $\begin{array}{l}\text { Average weight } \\
(\mathrm{mg})(n=20)\end{array}$ & $\begin{array}{l}\text { Hardness }\left(\mathrm{kg} / \mathrm{cm}^{2}\right) \\
(n=3)\end{array}$ & $\begin{array}{l}\text { Friability (\%) } \\
(n=6)\end{array}$ & $\begin{array}{l}\text { Thickness }(\mathrm{mm}) \\
(n=6)\end{array}$ & $\begin{array}{l}\text { Diameter }(\mathrm{mm}) \\
(n=6)\end{array}$ & Assay (\%) $(n=3)$ & $\begin{array}{l}\text { Disintegration } \\
\text { time* }(\min )(n=6)\end{array}$ \\
\hline $\mathrm{F} 1$ & $392.6 \pm 0.018$ & $7.08 \pm 0.14$ & $0.37 \pm 0.21$ & $4.26 \pm 0.023$ & $10.27 \pm 0.009$ & $99.3 \pm 0.32$ & $3.5 \pm 0.124$ \\
\hline $\mathrm{F} 2$ & $410.7 \pm 0.091$ & $7.17 \pm 0.29$ & $0.33 \pm 0.34$ & $4.26 \pm 0.040$ & $10.29 \pm 0.015$ & $99.1 \pm 0.73$ & $3.8 \pm 0.125$ \\
\hline F3 & $399.3 \pm 0.012$ & $6.92 \pm 0.14$ & $0.43 \pm 0.23$ & $4.25 \pm 0.016$ & $10.29 \pm 0.010$ & $99.54 \pm 0.36$ & $3.7 \pm 0.124$ \\
\hline $\mathrm{F} 4$ & $387.6 \pm 0.028$ & $7.17 \pm 0.14$ & $0.33 \pm 0.25$ & $4.25 \pm 0.024$ & $10.30 \pm 0.010$ & $99.52 \pm 0.37$ & $3.6 \pm 0.123$ \\
\hline F5 & $420.1 \pm 0.1$ & $7 \pm 0.0$ & $0.58 \pm 0.31$ & $4.24 \pm 0.023$ & $10.29 \pm 0.005$ & $99.57 \pm 0.17$ & $3.9 \pm 0.127$ \\
\hline F6 & $416.1 \pm 0.01$ & $7.42 \pm 0.14$ & $0.50 \pm 0.26$ & $4.25 \pm 0.026$ & $10.30 \pm 0.007$ & $99.59 \pm 0.21$ & $4.0 \pm 0.127$ \\
\hline F7 & $400.9 \pm 0.085$ & $6.92 \pm 0.14$ & $0.29 \pm 0.36$ & $4.27 \pm 0.012$ & $10.29 \pm 0.014$ & $98.72 \pm 0.11$ & $4.1 \pm 0.128$ \\
\hline F8 & $403.4 \pm 0.018$ & $7.08 \pm 0.29$ & $0.41 \pm 0.38$ & $4.25 \pm 0.040$ & $10.29 \pm 0.007$ & $99.64 \pm 0.18$ & $3.8 \pm 0.126$ \\
\hline F9 & $386.8 \pm 0.056$ & $7.50 \pm 0.0$ & $0.70 \pm 0.35$ & $4.24 \pm 0.030$ & $10.29 \pm 0.009$ & $98.68 \pm 0.27$ & $3.7 \pm 0.127$ \\
\hline
\end{tabular}




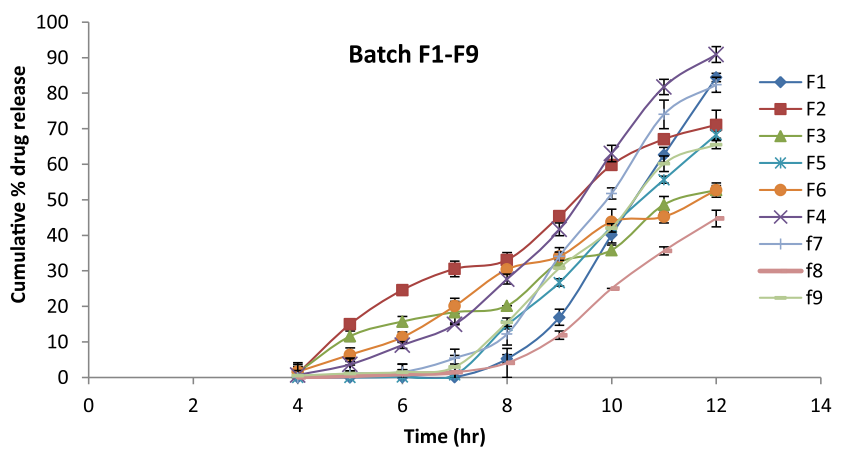

Fig. 3. In-vitro dissolution of all formulations.

chitosan, types of anionic polymers (pectin) used, \% coating and swelling behavior of the polymer. Thus in turn it mainly depends upon the amount of IPC used. The in-vitro release study was performed in $\mathrm{HCl}$ buffer ( $\mathrm{pH} \mathrm{1.2)} \mathrm{for} \mathrm{initial} \mathrm{first} 2 \mathrm{~h}$. Then the medium was replaced by acetate buffer ( $\mathrm{pH} 4.6$ ) for $1 \mathrm{~h}$, followed by phosphate buffer ( $\mathrm{pH} \mathrm{6.8)}$ ) for $3 \mathrm{~h}$. Study was continued for next $6 \mathrm{~h}$ in phosphate buffer ( $\mathrm{pH} 7.4$ ). Eudragit $\mathrm{S} 100$ is soluble at $\mathrm{pH}$ near 7.0 hence it dissolves at $\mathrm{pH} 7.4$ and leads to formation of porous surface at the coating layer which allows medium to diffuse into the core tablet to ruptures outer coat. Thus, the level of coating plays a very important role for in optimizing the formulation. At $\mathrm{pH} 1.2$ and $\mathrm{pH}$ 4.6 none of the formulations showed any release of drug due to enteric coating, while some batches started releasing the drug at $\mathrm{pH}$ 6.8. The release of drug was a maximum of $90.90 \%$ from batch $\mathrm{F} 4$ ( $2 \%$ IPC, $5 \%$ coating) near to $\mathrm{pH} 7$ at colon site. The ionic interaction between chitosan and negatively charged pectin was greatly reduced at colonic $\mathrm{pH}$ forming a loose network. This increased porous surface allowed entry of large amount of dissolution media leading to complete release of drug. Hence, it can be assumed that at $\mathrm{pH} 7.4$ of phosphate buffer, rapid dissociation of IPC membrane occurs which leads to drug release.

\subsubsection{Drug release data modeling}

The mechanism of drug release from enteric coated tablets containing PEC is complicated and not completely understood. Some systems may be classified as either diffusion or erosion controlled, while the most systems exhibit a combination of these mechanisms. ${ }^{17}$ The drug release data of all the 9 batches were mathematically analyzed using Korsmeyer-Peppas semiempirical model equation. The linearity of the model was evaluated by calculating the linear correlation coefficient $\left(r^{2}\right)$, while, the release mechanism was determined by evaluating the release exponent $(n)$.

Coefficients of correlation $\left(r^{2}\right)$ were used to evaluate the accuracy of the fit. The $r^{2}$ and $n$ values are given in Table 5. The $r^{2}$ values ranged between 0.9460 and 0.9759 for all the formulations. The $n$

Table 5

Results of kinetic model fitting for factorial batches (F1-F9).

\begin{tabular}{lll}
\hline Batch & \multicolumn{2}{l}{ Korsmeyer-Peppas } \\
\cline { 2 - 3 } & $r^{2}$ & $n$ \\
\hline F1 & 0.9595 & 0.686 \\
F2 & 0.9460 & 0.692 \\
F3 & 0.9516 & 0.632 \\
F4 & 0.9749 & 0.614 \\
F5 & 0.9759 & 0.650 \\
F6 & 0.9636 & 0.637 \\
F7 & 0.9180 & 0.620 \\
F8 & 0.9518 & 0.612 \\
F9 & 0.9514 & 0.555 \\
\hline
\end{tabular}

value were in the range of $0.555-0.686$ (i.e. $0.5<n<1$ ), indicating that, the release mechanism of theophylline from these matrices is an anomalous (non-Fickian) transport, which suggests that, both diffusion of the drug from the hydrated matrix and its own erosion modulate drug release. ${ }^{18,19}$

\subsubsection{Data analysis}

3.2.7.1. Data analysis for drug release at $4 h\left(Q_{4}\right)$. There was not much difference between actual and predicted values for all 9 batches. $r^{2}$ Value in plot of predicted $\mathrm{v} / \mathrm{s}$ observed responses was 0.9899 which indicated excellent fit. The response $\left(Y_{1}\right)$ obtained at three levels of the two independent variables $\left(X_{1}\right.$ and $\left.X_{2}\right)$ were subjected to multiple regression to yield a polynomial Eq. (4). Equation clearly reflects the wide range of values for coefficients $(b)$

$Q_{4}=0.11+0.47 X_{1}-0.17 X_{2}-0.22 X_{1} X_{2}+0.80 X_{12}-0.30 X_{22}$

In the present study, coefficients $b_{1}$ and $b_{2}$ possessed positive and negative sign indicating synergistic and antagonistic effect of variables $X_{1}$ and $X_{2}$ on response $Y_{1}\left(Q_{4}\right)$. Among two independent variables, $X_{1}$ (amount of PEC) has prominent effect ( $b_{1}=0.47$ and $p=0.0022$ ) on $Q_{4}$, whereas to some extent $X_{2}$ (\% coating) also affects the results $\left(b_{2}=0.17\right.$ and $\left.p=0.1299\right)$ in inverse manner. Significance ( $F$ value) is less than 0.05 . The high values of the coefficient of determination indicate a good fit i.e. good agreement between the dependent and independent variables. The coefficients $b_{1}$ was found to be significant at $p<0.05$ but $b_{2}$ was found to be insignificant at $p>0.05$.

3.2.7.2. Data analysis for drug release at $12 h\left(Q_{12}\right)$. The $r^{2}$ value for $Q_{12}$ in plot of predicted v/s observed responses was 0.9593 which indicated excellent fit. The $Y_{2}\left(Q_{12}\right)$ values observed for different batches showed wide variation i.e. values ranged from a minimum of $44.74 \pm 2.34 \%$ to a maximum of $90.90 \pm 2.25 \%$. There was not much difference between actual and predicted values. Eq. (5) refers to polynomial equation (full model) for response $\mathrm{Y}_{2}$.

$\begin{aligned} Q_{12}= & 0.105+0.474 X_{1}-0.168 X_{2}-0.217 X_{1} X_{2}+0.797 X_{12} \\ & -0.297 X_{22}\end{aligned}$

Coefficient $b_{1}$ and $b_{2}$ possessed positive and negative sign respectively which indicated positive effect of $X_{1}$ and antagonistic effect of $X_{2}$ variables on response $Y_{2}\left(Q_{12}\right)$. Independent variables, $X_{1}$ (amount of cross-linking) $\left(b_{1}=0.474\right.$ and $\left.p=0.0039\right)$ affects more prominently the $Q_{12}$ then $X_{2}$ (\% coating) ( $b_{2}=0.168$ and $p=0.4685)$ which has inverse effect on $Q_{12}$. Significance ( $F$ value) is less than 0.05 . The coefficient $b_{1}$ was found to be significant at $p<0.05$ and $b_{2}$ was found to be insignificant at $p>0.05$ Table 6 .

Two-dimensional contour plots and three-dimensional response surface plots are presented in Fig. $4 a-d$ which are useful tool to study interaction effects of the factors on responses. Fig. $4 a$ and $c$ exhibited non-linear pattern but with an increase in amount of PEC and \% of coating it also showed that amount of PEC has a comparatively greater influence on response variable $Q_{4}$ then $\%$ of coating. In contrast to the result of drug release at $4 \mathrm{~h}$ contour plot of drug release in $12 \mathrm{~h}$ varies in non-linear manner with an increase in amount of PEC and \% of coating (Fig. $4 \mathrm{~b}$ and d). However, the effect of $X_{1}$ (amount of PEC) seems to be more pronounced as compared with that of \% coating. The results was also confirmed through 3D response surface graph.

\subsubsection{Selection of optimized formulation}

From the polynomial equation and the contour plots, the optimized batch T1 was found. The optimum formulation was selected based on the criteria of attaining the constraints of variables 
Table 6

Summary of results of multiple regression analysis of $Q_{4}$ and $Q_{12}$.

\begin{tabular}{llllll}
\hline \multirow{2}{*}{ Dependent variable } & $Q_{4}=Y_{1}$ & & \multicolumn{2}{l}{$Q_{12}=Y_{2}$} & \\
\cline { 2 - 3 } & $P$ value & Coefficient & & $P$ value & Coefficient \\
\hline Intercept & 0.0030 & 0.11 & & 0.0390 & 67.57 \\
$X_{1}$ & 0.0022 & 0.47 & & 0.0039 & -14.43 \\
$X_{2}$ & 0.1399 & -0.17 & & 0.4685 & -2.63 \\
$X_{12}$ & 0.1299 & -0.22 & & 0.4081 & 3.68 \\
\hline
\end{tabular}

response. Upon 'trading of various response variables and comprehensive evaluation of feasibility search and exhaustive grid search, the formulation composition with amount of PEC (1.1\%) and coating (3\%) was found to fulfill the requisite of an optimum formula. In-vitro release data of optimized formulation are showed $92 \%$ theophylline release upon completion of $12 \mathrm{~h}$ but only $0.096 \%$ release in initial first $4 \mathrm{~h}$. Composition of the optimized batch T1 was also very economical as compared to the next best batch, F4, obtained from factorization.

\subsubsection{Validation of response surface methodology}

Two check points were selected for validation of response surface methodology from contour and response surface plots. For all of the 2 checkpoint formulations, the results of the dependent variables (Q4 and Q12) were found to be within limits.

\subsection{Ex-vivo release data}

The drug release data in presence of rat caecal contents are shown in Fig. 5. Rat caecal microflora was used because of the inherent similarity with human intestinal microflora. The main aim of the drug delivery system targeted to the colon is not only to protect the drug from being released in the physiological

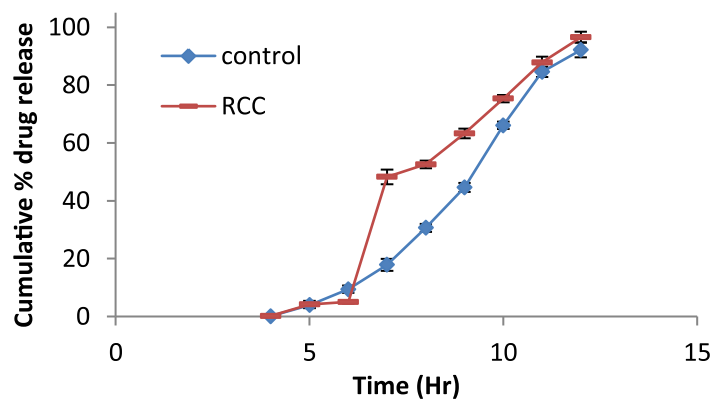

Fig. 5. Drug release profile of optimized formulation with and without rat cecal content. (No drug release in presence of rat caecal content was observed in $0.1 \mathrm{~N} \mathrm{HCl}$ and phosphate buffer 4.6 after $3 \mathrm{~h}$ ).

environment of stomach and small intestine, but also to release the drug in the colon after enzymatic degradation of polysaccharide. Hence, the in-vitro drug release studies were carried out in phosphate buffer ( $\mathrm{pH} 6.8$ ) and phosphate buffer ( $\mathrm{pH} 7.4$ ) containing $4 \%$ $\mathrm{w} / \mathrm{v}$ of rat caecal content. Optimized batch $\mathrm{T} 1$ shows $98.58 \%$ drug release in presence of rat caecal content. There was increase in drug release in the dissolution medium containing rat cecal content $(4 \%)$ as compared to control group (without rat caecal content).

\section{Conclusion}

Chitosan-pectin polyelectrolyte complex was prepared by simple interaction of positively charged chitosan with negatively charged pectin. The interaction was confirmed by DSC. The optimized batch consisting of PEC $(1.1 \%)$ and coating (3\%) showed $92.16 \%$ drug release within $12 \mathrm{~h}$. The ex-vivo drug release was found to be $98.58 \pm 1.92 \%$ in presence of rat caecal content.

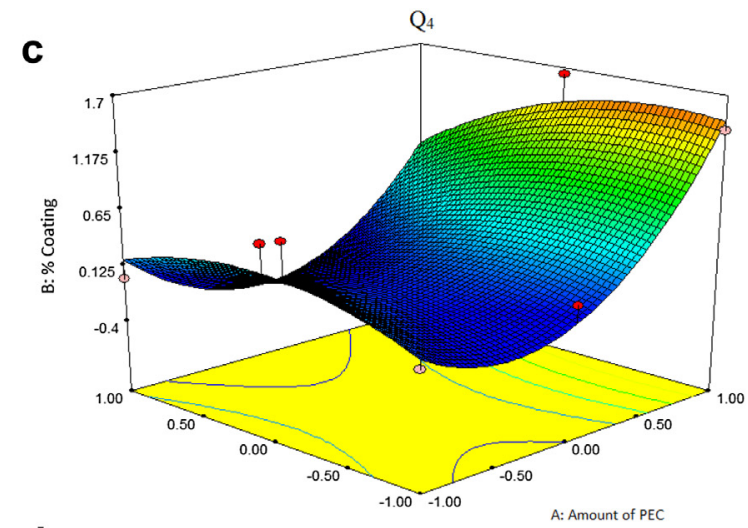

d

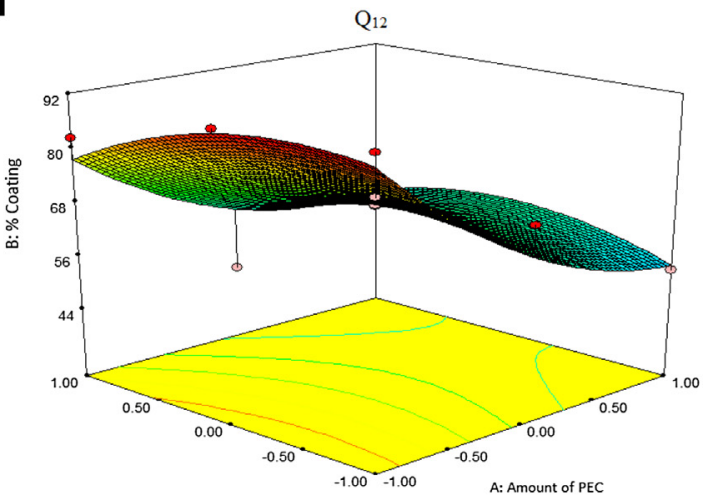

Fig. 4. (a): Contour plot $Q_{4}$, (b): contour plot $Q_{12}$, (c): response surface of $Q_{4}$, (d): response surface of $Q_{12}$. 


\section{Conflicts of interest}

\section{All authors have none to declare.}

\section{References}

1. Gent AN, Hamed GR. 198 - adhesive. In: Encyclopedia of Polymer Science and Engineering. 1st ed. New York: Wiley Interscience; 1985:476-517.

2. Jain A, Gupta Y, Jain SK. Perspectives of biodegradable natural polysaccharides for site-specific drug delivery to the colon. J Pharm Pharm Sci. 2007;10:86-128.

3. Kumar KV, Sivakumar T, Mani TT. Colon targeting drug delivery system: a review on recent approaches. Int J Pharm Biomed Sci. 2011;2:11-19.

4. Jose S, Dhanya K, Cinu TA, Litty j, Chacko AJ. Colon targeted drug delivery: different approaches. J Young Pharmacist. 2009;1:13-19.

5. Kalpana R, Kamath, Park K. Biodegradable hydrogels in drug delivery. Adv Drug Deliv Rev. 1993;11:59-84.

6. Geever LM, Cooney CC, Lyons JG, Kennedy JE, Nugent MJ, Devery S. Characterisation and controlled drug release from novel drug-loaded hydrogels. Eur J Pharm Biopharm. 2008;69:1147-1159.

7. Patel JK, Patel NV, Shah SH. In-vitro controlled release of colon targeted mesalamine from compritol ATO 888 based matrix tablets using factorial design. Res Pharm Sci. 2009;4:63-75.

8. Degussa. Specifications and test methods for Eudragit ${ }^{\circledR}$ L100 and Eudragit ${ }^{\circledR}$ S100. Retrieved on 23 March, 2011. Available from: http://www.solimide.eu/ de/pharmapolymers/eudragit/quality/spezifikationen_neu.Par.0001.TRow. 0006.TCell.0002.File.tmp/7.1.03_INFO7.3e_L100_S100_200409.pdf 2009.
9. Kothari CR. Research Methodology - Methods and Techniques. 2nd ed. New Delhi, India: New Age International Publishers; 2004:47-52.

10. Amin PD, Gupta SS, Prabhu NB, Wadhwani AR. Fast disintegrating dosage form of ofloxacin and metronidazole benzoate. Ind Drug. 2005;42:614-617.

11. USP 28-NF 23. The Official Compendia of Standards. Asian edition. United States Pharmacopoeial Convention, Inc; 2005:626-627.

12. Bigucci F, Luppi B, Cerchiara T. Chitosan/pectin polyelectrolyte complexes selection of suitable preparative conditions for colon-specific delivery of vancomycin. Eur J Pharm Sci. 2008;35:435-441.

13. Korsmeyer RW, Gurney R, Dueler EM, Bury P, Peppas NA. Mechanism of solute release from porous hydrophilic polymers. Int J Pharm. 1983;15:25-35.

14. Salve P. Development and in vitro evaluation colon targeted drug delivery system using natural gums. Asian J Pharm Res. 2011;1:91-101.

15. Ghaffari A, Navaee K, Oskoui M, Bayati K, Rafiee, Tehrani M. Preparation and characterization of free mixed-film of pectin/chitosan/Eudragit RS intended for sigmoidal drug delivery. Eur J Pharm Biopharm. 2007;67: $175-186$.

16. Abd El Gawad H, Ramadan EM, Soliman OA, Yusif RM. Formulation and in-vivo study of ketoprofen tablets prepared using chitosan interpolymer complexes. Bull Pharm Sci. 2012;35:1-16. Assiut University.

17. Siepmann J, Peppas NA. Modelling of drug release from delivery systems based on hydroxypropyl methyl cellulose. Adv Drug Deliv Rev. 2001;48:139-157.

18. Peppas NA. Analysis of Fickian and non-Fickian drug release from polymers. Pharm Acta Helv. 1985;60:110-111.

19. Peppas NA, Korsmeyer RW. Dynamically swelling hydrogels in controlled release applications. In: Peppas NA, ed. Hydrogels in Medicine and Pharmacy. 3rd ed. Boca Raton, U.S.A: CRC Press; 1986:109-136. 